\title{
The Challenges and Opportunities of Moderators in Converged Media
}

\author{
Jian DONG \\ Ph.D., Associate Professor (Chief Announcer), Shanghai Theatre Academy, Department of Broadcasting and TV Hosting \\ (College of TV \& Film Arts), Shanghai, China, Email: dongjian198@yahoo.com
}

\author{
Received: 03.05.2021 Accepted: 25.08.2021 $\quad$ Published: 09.10.2021 $\quad$ DOI: $\underline{\text { 10.47750/QAS/22.184.12 }}$
}

\begin{abstract}
With the continuous development of the Internet, the birth of new media and we-media has had a subversive impact on traditional media, the latter beginning to gradually merge into a new type of media, called "converged media". In such an era of blurred boundaries and extreme integration, the challenges that the moderators of traditional media are facing are tremendous. Based on an extensive literature review, as well as direct observation and a thorough analysis of case studies in China, the aim of the paper is to present the essential dilemmas the moderators of traditional media will have to encounter, such as how can they seize the opportunity in an intensively competitive environment or how can they self-improve to face the challenges of the current environment. For achieving the stated aim, the paper uses the anthropological methods of direct observation and analysis of visual social documents. Based on relevant case studies of successful converged media shows in China hosted by former announcer of traditional media, the main conclusion of the paper is that, in spite of the emergence of new online media, the oldstyle moderators still have a chance of adapting to the new environment granted that they build on their skills.
\end{abstract}

Keywords: composite talents, converged media, digital media, host, moderator, traditional media, we-media

\section{Introduction}

In the era of the continuous advancement of the Internet and innovative technology-mediated types of communication (Duan et al., 2020), new media and we-media have definitely acquired the potential of dethroning traditional or old media, shaking their long-established place, and even disrupting the foundations of the simple act of communication (Steensen \& Westlund, 2021). In the last decades, both TV stations, radio stations and newspapers have suffered some negative impacts in terms of their forms and substance, as well as their population reach. The most frequent critique to traditional media and, implicitly, the widespread praise of new media, refers to the fact that the former is too programmatic and restrictive, while the latter is very casual and inclusive, rather implying that new and traditional media are exactly two opposite medias. New media, broadly defined as "computable" media (Manovich, 2002), and we-media referring to media content created and distributed by the audiences themselves (Bowman \& Willis, 2003), have developed rapidly because they have capitalized on the weaknesses of traditional media. Their "short", "fast" and "fragmented" content characteristics are in line with the "fast food-type" culture of modern audiences, which are rather interested in quantity than quality, expressing their willingness to choose the simplest and easiest way to understand news, to get informed and entertained.

In an environment in which new media gain momentum and extend their scope, both traditional media as a whole and the "classical" moderators are facing numerous challenges. Primarily, many new media programs no longer need the moderators' role, as presumably cadres activating in any other industry can become moderators, or even media creators, producers, and distributors. Secondarily, new digital media do not need "elites" to create shows, set the cultural trend, educate the public and distribute programs, as nowadays virtually every individual can produce media content in various types of environment, including at home (Bolter, 2019).

Nevertheless, just when many people thought that traditional media might get to an end, the "converged media" was born, combining the elements of both new and old media, as well as those of we-media. The emergence of converged media prompted to a revival of traditional media, bringing hope to "oldfashioned" media producers, moderators, and broadcasters that, as long as they took advantage of their professional strengths and maximized them, and learned the advantages of new media, they would definitely be able to survive in the new era of converged media. Moreover, they might have a say in emphasizing the benefits, as well as the potential disadvantages of the new forms of media, debating whether having a more diverse content is intrinsically good, or whether any piece of information, if distributed, is inherently true and reliable.

The paper aims at identifying the obstacles and hardships encountered by traditional-style educated media moderators in the current highly digitalized environment, in an attempt to derive the most important skills that are required to deliver successful digital content. Although the literature abounds in studies describing the emergence, characteristics, and impact of new media or converged media, some of the main protagonists of digital media, namely the moderators or show hosts, are left aside from inquiries with a valuable practicality in scope. Therefore, the central research purpose is that of pinpointing the most valuable competences that can transform an old-style presenter or announcer into an outstanding host of the new, converged media, with large audiences. By carefully observing and analyzing the skills and aptitudes displayed by former 
traditional media moderators, who shifted from old to new media content and currently host successful interactive shows or programs, the paper will present both the challenges and opportunities of the contemporary media environment.

\section{Materials and Methods of Analysis}

Starting from the new trend in media studies, according to which anthropological and sociological methods can offer relevant manners of investigating and understanding how and why media content is created, produced, disseminated, and consumed (Pertierra, 2018), the paper uses direct observation and social content analysis of several exceptionally successful entertainment shows in China in order to pinpoint the main skills and abilities of the shows' hosts. Social documents analysis, mainly imagery and visual content, is an important and innovative tool of qualitative research, that can provide valuable insight into the research topic (Grant, 2019). Moreover, the direct involvement into the field of research and particular interpretation of significant aspects such as how moderators perform, how the public perceives a media show, or how the public thinks, feels and reacts are informative tools of media studies (Luvaas, 2021). As a result, the analysis techniques included the direct observation of the analyzed Chinese popular media shows, with millions of viewers, such as Jin Xing Show, Qi Pa Shuo, Zhong Guo Shi Ci Da Hui, Lang Du Zhe, or Fei Cheng Wu Rao. Based on tens of hours of media content observation and a thorough analysis of images and text or verbiage exhibited by the hosts, during the shows, the paper attempts to extract the particular strengths and talents of traditional moderators that generated the strongest positive emotions and, implicitly, supportive reactions among the audiences, translated into the biggest number of followers or viewers. Given that the new, converged or online media content is primarily evaluated depending on its capacity of creating, expressing and spreading emotions (Serrano-Puche, 2016), it becomes obvious that the performance of moderators should be assessed along this line.

The paper also involves and extensive literature review in order to highlight the feature and significance of converged media. In a world hugely impacted by the Internet and the digitalization of almost all aspects of life, media institutions and platforms are becoming more various, methods of communication are increasingly diverse, and the ways and channels of receiving information are boosting their number and variety. The evolution of new media and we-media has had a huge impact on traditional media, as the latter's reach has fallen enormously while the former has acquired new audiences and followers (Wang, 2020). While traditional media has too many limitations, and audiences can only watch programs according to specified content and time, new media offers unlimited possibilities, people being able to choose what they want to see and hear, empowered with an "active power" to no longer accept the "passive" viewing mode brought by traditional media.

Media convergence simply refers to the process through which traditional media and communication industries adapt to the new hyper-technologized reality (Dwyer, 2010), by integrating the advantages of radio, television, and newspapers, so that their functions, means, and values can be fully readjusted and improved. The integration of traditional, new and we-media platforms, capitalizing on their resources, content, and strengths, can definitely lead to a win-win situation, in which all these three major types of media can co-exist.

Although the traditional media might have not been prepared for digitalization, for freely sharing their content, or for allowing all stakeholders to participate in content production (Nightingale, 2007), it is now clear that old, new and we-media will rather manage to strive together, as the integrated media environment embraces the professional reliability of traditional media, the diversification of new media, and the individual innovation of wemedia, making them complementary, although sometimes mutually exclusive. Instead of replacing the old media, the new types of media will rather co-evolve with the former (Finnemann, 2008), in a complex process of integration that does not necessarily imply merging or assimilation. Metaphorically speaking, the three major medias, running in three straight lines, will cross each other, will blend, but will never merge into one single line.

One of the biggest results brought by converged media is that the boundaries between different type of media have changed from clear to blurry (Landert, 2014). Although in the era of converged media the resources of media are more abundant, both in terms of content, means of communication, and stakeholders, they are, at the same time, more blurred. For instance, actors cross the border to moderators, moderators cross the border to directors, directors cross the border to "Internet celebrities", and "Internet celebrities" cross the border to proprietors.

Although the blurred boundaries of media or the crossindustry phenomenon might bring benefits, major drawbacks should also be taken into account. For instance, the new types of media are more focused on variety and quantity than on quality, and, as frequently stated by experts in psychology and behavioral economics (Schwartz, 2016), "more is not always better". Nowadays, the production of all types of media might be far greater than people's demand, thus leading to a "decision paralysis" and, ultimately, to a state of loss and fear. In the past, people spent time watching programs, now they spend more time choosing programs. Equally important, at present, people might choose to watch a program based on that program's advertising campaign or on the recommendations from friends, instead of discovering it by themselves. Therefore, the success of the program's packaging promotion has become the most important factor in the popularity of modern media programs, while the content is no longer the key to attract people's attention.

In such a converged media environment, the future of traditional moderators might be imperiled, demanding their fast and complete adaptation to the new requirements. Although this is not an easy process, the success stories of moderators who managed to do just that is of great interest.

\section{Analysis and Results}

The emergence of new media and we-media has greatly impacted traditional media specialists, especially TV moderators. Previously, a widespread opinion among the general public was that moderators of traditional media only needed good voice, nice appearance and satisfactory communication skills. Nevertheless, in the age of the Internet, viewers no longer accept this single mode of hosting, and TV moderators are no longer the sole communicators, nor are they the entertainers or the main figures of the show. Instead, they have become announcers, compelled to interact with their audiences, even in the most popular television reality shows.

At the same time, the birth of new media has offered the opportunity for virtually everyone to become a host or a moderator on the alleged condition that they have unique personality and creativity. For example, the worldwide famous dancer Jin Xing crossed the boundary to become one of the most popular entertainers, hosting the weekly variety production Jin Xing Show, watched by approximately 100 million people every week (Willige, 2017), while Chinese traditional producer and director Ma Dong changed his role to become one of the hosts 
of the most acclaimed online talk show Qi Pa Shuo, with millions of followers (Koetse, 2017).

Moreover, "old" skills, such as speaking standard Mandarin and having presentation and communication abilities are no longer mandatory, while static broadcasting is not satisfactory for modern audiences anymore. Concerns regarding the future role of moderators in converged media are not new in China, as indicated by the famous Zhejiang Station TV moderator with the stage-name Hua Shao, who sorrowfully and rhetorically asked whether moderators will be more than "speaking machines, without attitudes and values" (Shao, 2015), always ready only to read advertisements and mundane announcements. And, indeed, a pressing question is whether the moderators or the hosts will only be a "megaphone", without being allowed to express their personal opinions or comments.

In spite of a potentially gloomy future for traditional moderators, the emergence of new media and we-media has curtailed the limitations of "old" media and given the moderators novel and more favorable circumstances to express themselves. Even though moderators trained in Mandarin and broadcasting might be directly threatened by the new media trends, they still have valuable experience and proficiency that could be used to take advantage of the new opportunities brought about by converged media. Hope is also given by the former television presenters who successfully managed to become the beloved hosts of internationally known Internet shows, such as: the popular Cai Kangyong or Kevin Tsai, who had the opportunity to express his opinions and views as one of the hosts of Qi Pa Shuo talk show (Fan, 2019); the highly awarded Qing Dong, who reinvented herself by hosting the well-known Chinese poetry competition Zhong Guo Shi $\mathrm{Ci} \mathrm{Da} H$ Hi or the sensational literature talk show Lang Du Zhe (Li, 2017); or the acclaimed Meng Fei, with his worldwide debated dating show Fei Cheng Wu Rao (Custer, 2019). All these examples, and many other, are a clear evidence that converged media did not bring the end of moderators, but provided new possibilities to them.

The adaptation to the new reality is nevertheless complicated and even sinuous, as the moderators need to display and constantly improve a series of composite skills and qualities. Converged media has brought dramatic changes to traditional moderators, as their focus has shifted from single to composite, and from program to project. The new media field that moderators need to get involved in is getting more complex and challenging, given their "short, flat, and fast" features. The Internet has profoundly changed people's viewing and listening habits, therefore in terms of information and communication there is an increased necessity for any news or entertainment provider to find the best way of transferring the most effective message in the shortest period of time. The presenting and communication skills of traditional moderators can no longer meet the taste of converged media audiences or fit the rhythm required by the modern public, so malleable abilities and a lightmindedness in adapting the already acquired know-how are required.

Friendliness and affability are personal attributes that audiences are highly receptive to nowadays, and, given the decline of formal restrictions in converged media, moderators or hosts can now express themselves on the show and dispaly their diversity. From an unsophisticated presenter who was only responsible for simply transmitting a message in the past, the moderator has now become a versatile and multi-talented person. In addition to being responsible for hosting the show, the moderator must also allow and encourage interactions with the public, review and summarize the theme at the appropriate time, control the scene, and even set the mood, all of these reflecting the heterogeneous talents of a moderator. Equally important, appropriate performances, such as acting, singing, and imitating, can be included in the process of hosting, such as fully demonstrated by the assistant host Xiao Nan in The Jin Xing Show (Sheehan, 2015), or Xie Na in The Happy Camp, who even established a record for the biggest number of followers on the Chinese microblogging website Weibo (Swatman, 2017).

Emotions have also become important and indispensable features of converged media, as audiences appreciate performances and wordings that are more able to arouse them and touch their feelings (Serrano-Puche, 2016). Therefore, a moderator who can convey the story or the content of the show with heart rather than with cold mind is genuinely communicating with the audience emotionally. Moderators who want to express their emotional intelligence must understand the entire program or show, by fully participating in all the stages, from pre-planning to post-production, from advertising to publicity. The complete involvement of the moderators in all the stages of a show requires them to add new media skills to their portfolio, or even to become so proficient as to produce their own programs, as already proven by famous moderators such as Chen Rong with her "infotainment" programs (Kong, 2014).

\section{Discussion}

Given the characteristics and requirements of the converged media, it is essential to identify the qualities necessary for performing in the current media environment. Based on the results of direct observation and content analysis, three main categories of skills seem to have the biggest impact on the success of moderators's performance, namely cognitive and language skills, analytical and behavioural skills, and technical and planning skills. Although some of these skills are not unfamiliar to TV moderators, they need to be refined and enhanced in order for them to meet the preferences and expectations of the modern audiences.

\subsection{Cognitive and language skills}

Specific language skills or, more generally, communication skills, as well as a sharp and fast thinking proficiency have long been necessary abilities for television and radio presenters, yet the new converged media landscape poses additional challenges in terms of "basic" skills for a "traditional" moderator. It is almost commonplace to admit that the moderator is the "bridge" or the mediator between the source and the target of a message, or between media and audience, therefore the quality of the moderator's language skills in a program is extremely important. The wide category of language skills of the moderator includes various elements, all of them equally important for a good performance, such as language flow, semantics, tone of voice, use of words, or form (Stephenson et al., 2005). Given that the audience receives information depending on moderators' language skills, it results that they must have a good grasp of the fluency of language, language perception, the meaning and form of language, so as to make the language more attractive, appealing and successful.

Moreover, besides having good basic language skills, a moderator must accurately convey the semantics to the audience, yet in the current "fast food-type" culture audiences are no longer willing and prepared to listen to serious language and talk gradually, but are more inclined to accept simple, crude and direct content. Accordingly, in the era of converged media moderators must integrate the valuable content and meaning of language with the modern "short, flat and fast" rhythm to make the language more interesting and achieve the desired efficient communication.

At the same time, given the importance of emotions in today's communication, and of closeness between the sender and a receiver of a message (Kong, 2014), moderators must 
express and provoke true feelings by appealing to short and meaningful words, without reducing or lowering the quality of the language. For example, the three moderators and contestants in the show Qi Pa Shuo, also known as U Can You BB, perfectly combined the major language skills with the characteristics of modern "short, flat and fast" culture, thus being able to communicate effectively to the audience. For instance, Cai Kangyong used gentle words and sincere emotions to convey his views to everyone, Gao Xiaosong shared his allusions using earthly language in a self-deprecating way, while Ma Dong used ridicule and short meaningful phrases to comment and summarize the players' speeches (iQiyi, 2020). Their scene behaviors and performances are informative examples of how moderators can adapt to the new media landscape and speak not only good language, but vivid language, as well as integrate solid language skills with humorous expressions to achieve meaningful phrases.

Considering the complex relation between language and thinking (Balari \& Lorenzo, 2018), it is indisputable that thinking skills are also important for the moderators in their efforts to convey a message. Although quite simplistic, yet perfectly appropriate for the Chinese culture, the distinction between logical thinking and image thinking is helpful for understanding the supplementary hardship encountered by moderators. While logical thinking is usually appealed to in science, image thinking, involving visual, verbal, or combined techniques of thought expression, is regularly invoked in art or artistic creation (Cheng, 2017). As a distinguished moderator needs to work with mind and heart, the thinking must use both abstract logic and rich imagination in order to fascinate the audiences and make them "see things" via language.

Assuming that the internalized language refers to the thinking process or a component of the mind, while the externalized language is the expression of the mind or the verbalization of the thinking (Chomsky, 1986), then the cognitive abilities of a person strongly influence the form and force of the language. In the new media landscape, higher requirements have been placed on moderators to continuously strengthen and improve their cognitive abilities in order to better adjust to the cultural environment, objectively understand information, observe things, and respond to the demands of the audience. In order to stand out in the era of converged media and attract the audience, moderators must have a distinctive or even divergent way of thinking and come up with in-depth, yet out-of-the-box ideas or interpretations of the information. In a world with audiences craving for novelty and permanently seeking for high intensity sensations, the moderators' creativity and divergent thinking are of uttermost importance (Hirschman, 1980). Nevertheless, a good or desired way of thinking must be unexpected, but also reasonable and justified, otherwise the message will only become a nonsense phrase or word.

\subsection{Analytical and behavioral skills}

A famous quote from a science fiction novel, largely used nowadays to describe the various domains of a highly digitalized world, pretends that "form does not matter, [while] content is everything" (Bradbury, 1967). Original and interesting content is always one of the most important keys to gain and retain the audience, and the moderators need to cultivate their analytical skills in order to adjust the best program composition for their audience's preferences. Although people might choose programs based on the content marketing and advertising, preferences for media stars, and follow-ups on social media, good content remains essential for keeping the audience interested. For example, many Internet celebrities and shops are using hype to gain attention overnight, yet no one can guarantee that the success will last even in the absence of a genuine talent, or that the audience will be able to distinguish "noise" from opportunities and quality content (Bernstein, 2001).

In addition to determining the content of the program, the moderators need to choose speech that is both entertaining and informative. The content of the program should always be integrated with the content that the moderator wants to express to better render the theme or the message. While an actor or a media star relies heavily on a marketing campaign to gain attention, the key to becoming an icon is always doing your job with commitment, as a good work speaks for itself. The moderators need to attract the audience with talent and skills, yet the essence of them becoming the ultimate reason for watching the show is whether the content is contagious. For example, the Zhong Guo Shi Ci Da Hui show, or the Chinese Poetry Conference, hosted by Qing Dong is a cultural program where virtually anyone can participate by reciting poetry (CCTV, 2020). In the era of variety entertainment, the program is aimed at promoting traditional culture and bringing back the beauty of Chinese poetry into the public attention. Although the show might not seem to be in line with the mainstream entertainment preferences, it has become largely appreciated both among the domestic audience and internationally, inspiring people to rediscover the refinement and spirituality of Chinese ancient poems (Yu, 2017). Beside the fascinating composition of the program, the wonderful performance of the host Qing Dong is also praised, demonstrating that the content of the program and the performance of moderators are enough to stand out and become a symbol of cultural programs, even in the era of converged media.

Equally important is the art of hosting, and the behavioral skills of the moderators are of great importance in this regard, as they are the hosts of the show but not the protagonists, the guides of the audience but not the leaders. The cunning of the moderators consists mainly in the fact that the guests and the audience should be put first in the program, without minimizing their role. Given that the primary purpose of the audience watching the program is to be entertained by the content and the guests of the show, the moderator has the honorable task of bringing familiarity on the scene and mediating the connection between all the participants.

Interactivity and familiarity are particularly important in the converged media environment. While the traditional media moderators always preserved a social distance from their audience and maintained a cold attitude, the Internet has reduced this typical aloofness and endorsed the engagement of the public. The host of converged media must be able to step up to the audience, so that the viewers can truly feel that they are an active part of the show, as nowadays no audience would be willing to watch a tight moderator preaching in front of them.

\subsection{Technical and planning skills}

With the integration of different media and the intersection of different professions, moderators need to acquire multiple capabilities as a single talent is not enough anymore for being successful. In addition to their exceptional personal skills, core knowledge, and artistic education, the moderators of the new media need to demonstrate solid digital literacy (Kaul, 2013). Having a new media mindset, although essential, is insufficient for overcoming the challenges of the current environment, moderators being compelled to achieve digital fluency by learning to use network and social media tools, prop equipment, media hardware, or application software. The digital technologies and channels for disseminating media content are constantly changing at an exponential rate, and for that reason, moderators are under a huge stress for keeping the pace with 
the technological revolution.

Moreover, traditional media do not possess the monopoly over media industry as it used to be case in the past, and the volume of accessible content, as well as the amount and type of devices and platforms for digital delivery, expand continuously for an increasingly bigger number of consumers or viewers. In June 2020, China has reached an Internet penetration rate of 67.0 per cent and a total number of 940 million netizens, who access the huge variety of media content through mobile phones (99.2 per cent), desktop computers (37.3 per cent), laptop computers (31.8 per cent), television sets (28.6 per cent), and tablet computers (27.5 per cent). With 888 million Chinese citizens using applications of online short and long-format video, including video clips, and 562 million netizens using live streaming platforms, of which 186 million, or almost 20 per cent of all Internet users watching host live shows (CNNIC, 2020), it is clear that the digital media market is huge, putting a supplementary pressure on digital content creators and producers. Under the competitive pressure of short and longform video applications, which can be used by virtually anyone, moderators must keep the pace with technology and become literate in various fields, at the same time improving their talents and competence for discovering and satisfying their viewers' preferences, and, why not, even "educating" their audiences by shaping their tastes.

Another technical area in which moderators must have proficiency is planning and production, as performing live on the stage implies knowing all the phases of the show and the roles of all participants. If they want to be completely integrated into the show and effectively communicate important information or transmit impactful messages to the audience, the moderators must participate directly to the process of data collection and understand the meaning of communication. By being involved in all the stages of a media product, the image of the moderator becomes integrated with the image of the show, and the two, moderator and show, become inseparable in the eyes of the viewers. For instance, the simple mentioning of Zhong Guo Shi Ci Da Hui show evokes the name and image of its host, Qing Dong, in the minds of the followers, and vice versa. Qing Dong participates in the pre-production and production of the show and, as a result, she is able to always captivate the audience by setting the rhythm, creating emotions with a vivid language and engaging narratives.

\section{Conclusion}

A great piece of practical advice is to grasp the essence of the past and then move on to the present in order to be prepared for the future, and this guidance is as timely and adequate as ever for the moderators in the age of converged media. Each epoch has its advantages and disadvantages, and the individuals who succeed persistently are those who are able to surmount adversities and seize opportunities. The new digital media landscape has brought great challenges and even threats to traditional moderators, nevertheless they also have the chance of constantly learning and improving in order to successfully adapt to this unfamiliar environment.

Although the future of the moderators is demanding and they need to acquire new skills, their core competencies will remain essential. The moderators should learn from the experience and advantages of traditional media, and then move on in the direction of new media. Long-established abilities and talents, such as speaking proficiency and thinking dexterity are still valuable, yet they need to be polished and adjusted to the characteristics of converged media, as the new audiences are nowadays more that simple receptors of messages, but active participants in the media content creation and distribution.
Exquisite and finely detailed language, once a precondition for entering the media field, is not necessary anymore, as large audiences are rather inclined to be moved by simple and direct affective messages. Similarly, analytical and behavioral skills are not entirely new, yet a moderator or host should refine them in order to be able to keep the public both informed and entertained, both attentive and relaxed. For instance, the moderator must bring familiarity on the stage, and act not as a distant conveyor of a message, but as a companion of both the guests and the public, so the audiences would feel that they are part of the show. The third set of professional competences, namely technical and planning skills, are equally novel and demanding, requiring traditional moderators to learn and display solid digital literacy, by operating with various digital technologies and tools.

Given the huge quantity and variety of sources of information made available by the new media, the need for a moderator with a professional background to lead or guide the audience and spread the most valuable and reliable information might be as actual and important as possible. However, moderators should become aware of their usefulness in the new media context, grasp the opportunities offered by converged media, and redefine their place within the new information and communication environments.

\section{References}

[1]. Balari, S., \& Lorenzo, G. (2018). The internal, the external and the hybrid: The state of the art and a new characterization of language as a natural object. Glossa: a Journal of General Linguistics, 3(1). doi: $10.5334 /$ gjgl.330

[2]. Bernstein, R. (2001). Navigate the Noise. Investing in the New Age of Media and Hype. New York: John Wiley \& Sons

[3]. Bolter, J. D. (2019). The Digital Plenitude. doi: $10.7551 /$ mitpress/9440.001.0001

[4]. Bowman, S., \& Willis, C. (2003). We Media. How audiences are shaping the future of news and information. Reston: The Media Center at the American Press Institute.

[5]. Bradbury, R. (1967). The Illustrated Man. New York: Bantam Books.

[6]. Zhong Guo Shi Ci Da Hui (2020), Seasons 1-5 (2016-2020). CCTV Network. Retrieved November 15, 2020, from https://bit.ly/3s4MwUZ.

[7]. Cheng, Z. (2017). Morphological Semantics, Chinese Edition. Beijing: Peking University Press.

[8]. China Internet Network Information Center (CNNIC). (2020). Statistical Report on Internet Development in China (September 2020). Retrieved December 7, 2020, from https://bit.ly/3qDPpMb.

[9]. Chomsky, N. (1986). Knowledge of Language: Its Nature, Origin, and Use. New York: Praeger Publishers.

[10]. Custer, C. (2019). "Fei Cheng Wu Rao: China's Hottest Dating Show". Live About, Dot dash Press. Retrieved December 4, 2020, from https://bit.ly/39VipJx.

[11]. Duan, P., Zhang, L., Song, K., \& Han, X. (2020). Communication of Smart Media. doi: 10.1007/978-981-15-9464-9

[12]. Dwyer, T. (2010). Media Convergence. Berkshire: Open University Press.

[13]. Fan, S. (2019). "China's Hottest TV Show Right Now is Striving to Provide Space for Mainstream Debate". RADII Media, China. Retrieved October 9, 2020, from https://bit.ly/3twmDPv.

[14]. Finnemann, N. O. (2008). "The internet and the Emergence of a New Matrix of Media". Paper presented at the Association of Internet Researchers (AolR) 9.0 - Rethinking Community, Rethinking Place. Copenhagen: The IT University of Copenhagen.

[15]. Grant, A. (2019). Doing Excellent Social Research with Documents. Practical Examples and Guidance for Qualitative Researchers. New York: Routledge.

[16]. Hirschman, E.C. (1980). "Innovativeness, Novelty Seeking, and Consumer Creativity". Journal of Consumer Research, 7(3), 283295. Retrieved December 17, 2020, from http://www.jstor.org/stable/2489013.

[17]. iQiyi Network (2020). I Can I BB, Seasons 1-7 (2014-2020). 


\section{GENERAL MANAGEMENT}

Retrieved December 20, 2020, from https://bit.ly/3dj7A69.

[18]. Kaul, V. (2013). Journalism in the Age of Digital Technology. Online Journal of Communication and Media Technologies, 3(1). doi: $10.29333 /$ ojcmt/2414

[19]. Koetse, M. (2017). "The Success of China's Hit Talk Show Qi Pa Shuo (U Can U Bibi)". What's on Weibo. Retrieved September 14, 2020, from https://bit.ly/3caOleq.

[20]. Kong, S. (2014). Popular Media, Social Emotion and Public Discourse in Contemporary China. doi: 10.4324/9781315867243

[21]. Landert, D. (2014). "Blurring the Boundaries of Mass Media Communication? Interaction and User-Generated Content on Online News Sites". In: Tyrkkö, J., \& Leppänen, S. Texts and Discourses of New Media. Helsinki: Varieng.

[22]. Li, P. (2017). "TV program 'Readers' rekindles passion for literature across China". China Daily. Retrieved October 9, 2020, from https://bit.ly/2MxcpOr.

[23]. Luvaas, B. (2021). "Affect and Autoethnography in Social Media Research". In Cunningham, S., \& Craig, D. Creator Culture. An Introduction to Global Social Media Entertainment, New York: New York University Press, pp. 57-74.

[24]. Manovich, L. (2002). The Language of New Media. Cambridge: MIT Press.

[25]. Nightingale, V. (2007). "New Media Worlds: Challenges for Convergence". In Nightingale, V., \& Dwyer, T. (Eds). New Media Worlds: Challenges for Convergence. Melbourne: Oxford University Press.

[26]. Pertierra, A.C. (2018). Media Anthropology for the Digital Age. Cambridge: Polity Press.

[27]. Schwartz, B. (2016). The Paradox of Choice: Why More Is Less, Revised Edition. New York: HarperCollins Publishers.

[28]. Serrano-Puche, J. (2016). Internet and emotions: New trends in an emerging field of research. Comunicar, 24(46), 19-26. doi: 10.3916/c46-2016-02
[29]. Shao, H. (2015). "Does the host have a future?" (in Chinese). Weibo, Sina Corporation. Retrieved October 20, 2020, from https://bit.ly/3rfMSI6.

[30]. Sheehan, M. (2015). "Meet the Badass Transgender Talk Show Host Who Wants to Be China's Most Influential Woman". Huffington Post. Retrieved December 5, 2020, from https://bit.ly/3cQxjT6.

[31]. Steensen, S., \& Westlund, O. (2021). What is Digital Journalism Studies?. London: Routledge.

[32]. Stephenson, A.R., Reese, D.E., \& Beadle, M.E. (2005). Broadcast Announcing Worktext: Performing for Radio, Television, and Cable, Second Edition. Oxford: Elsevier.

[33]. Swatman, R. (2017). "Happy Camp hosts He Jiong and Xie Na set record for their Weibo followings". Guinness World Records Greater China. Retrieved December 5, 2020, from https://bit.ly/360NOX6.

[34]. Wang, T. (2020). Influence of News Reports on Different Media Platforms-Taking People's Daily as an Example. Proceedings of the 2020 3rd International Conference on Humanities Education and Social Sciences (ICHESS 2020). doi: 10.2991/assehr.k.201214.510

[35]. Willige, A. (2017). "From male colonel to female ballet dancer the extraordinary story of Jin Xing". World Economic Forum. Retrieved September 14, 2020, from https://bit.ly/3ofFaMj.

[36]. Yu, S. (2017). "Analysis on Communication Effects of Cultural Quiz Show". Advances in Social Science, Education and Humanities Research, Vol. 144, 3rd International Conference on Arts, Design and Contemporary Education, Atlantis Press. 